\title{
Prediction of Reperfusion and Infarct-Related Artery Patency after Thrombolysis in Acute Anterior Myocardial Infarction by Degree of P Wave Dispersion on ECG
}

\author{
Md. Monir Hossain Khan1, Md. Afzalur Rahman², Abdullah AI Shafi Majumder³, Md. Toufiqur Rahman", \\ Md. Monsurul Haque ${ }^{5}$, Khondker Shaheed Hussain ${ }^{6}$, Golam Rahman Mallic ${ }^{7}$, Mohammad Khalilur Rahman Siddiqui ${ }^{8}$, \\ Md. Sariful Islam ${ }^{9}$, Md. Azijur Rahman ${ }^{10}$.
}

\begin{abstract}
Background: The prognosis of patients with persistent occlusion of the infarct related artery (IRA), despite lytic therapy is poor. Early detection of successful reperfusion and IRA patency is of great importance in terms of prognosis and identification of candidates for rescue percutaneous coronary intervention (PCI). $\mathrm{P}$ wave dispersion (PWD), a new parameter measured before and after fibrinolytic therapy (FT) is supposed to predict successful reperfusion in patients with anterior acute myocardial infarction (AMI).

Objectives:To examine the prediction of successful reperfusion and infarct related artery (IRA) patency by measuring $P$ wave dispersion in 12-lead surface ECG.

Method:132 patients were selected and divided into two groups on the basis of ST segment resolution (STR) after 120 minutes of thrombolysis. Group I: patients with STR $>70 \%$; Group II: patients with STR $<70 \%$. All patients underwent coronary angiography (CAG). IRA patency was considered if TIMI flow grade was $>2$.

Results: Mean age of the successfully thrombolysed group was $49.12 \pm 9.54$ and mean age of failed
\end{abstract}

thrombolysis group was $52.08 \pm 8.23$ years. Though higher age was associated with failed thrombolysis and it was statistically insignificant $(p=0.06)$. Patients with higher BMI showed no significant difference in thrombolysis.

It was observed that diabetes mellitus and dyslipidemia were significantly higher in group II patients $(p=0.04$ and $p=0.03$, respectively). The mean level of PWD after 120 minutes of thrombolysis (PWD120) was statistically significant $(p=0.001)$ between two groups. After multivariate regression analysis PWD120 was found to be the significant predictor of ST segment resolution as well as IRA patency $(\mathrm{OR}=1.101 ; 95 \% \mathrm{CI}=1.012-$ 1.240; $p=0.01$ ).

Conclusion: $P$ wave dispersion (PWD) in patients receiving thrombolytic therapy can be a predictor of successful reperfusion and patent infarct related artery (IRA). PWD values, in combination with other reperfusion parameters, can contribute to the identification of rescue $\mathrm{PCl}$ candidates.

Key words: Myocardial Infarction, Reperfusion, ECG, Streptokenase.

(Bangladesh Heart Journal 2017; 32(2) : 100-105)

1. Registrar, Department of Cardiology, National Institute of Cardiovascular Diseases (NICVD), Dhaka, Bangladesh.

2. Director \&Professor, National Institute of Cardiovascular Diseases (NICVD), Dhaka, Bangladesh.

3. Ex-Director \& Professor, National Institute of Cardiovascular Diseases (NICVD), Dhaka, Bangladesh.

4. Professor, Department of Cardiology, National Institute of Cardiovascular Diseases (NICVD), Dhaka, Bangladesh.

5. Associate Professor, Dept. of Cardiology, National Institute of Cardiovascular Diseases (NICVD), Dhaka, Bangladesh.

6. Associate Professor, Dept. of Cardiology, National Institute of Cardiovascular Diseases (NICVD), Dhaka, Bangladesh.

7. Junior Consultant, National Institute of Cardiovascular Diseases (NICVD), Dhaka, Bangladesh.

8. Junior Consultant, National Institute of Cardiovascular Diseases (NICVD), Dhaka, Bangladesh.

9. Post-Graduate Fellow, National Institute of Cardiovascular Diseases (NICVD), Dhaka, Bangladesh.

10. Junior Consultant, National Institute of Cardiovascular Diseases (NICVD), Dhaka, Bangladesh.

Address of Correspondence: Md. Monir Hossain Khan, Registrar, Department of Cardiology,National Institute of Cardiovascular Diseases (NICVD), Dhaka, Bangladesh.Cell phone: +8801711225521; E-mail: drmmhkhan@gmail.com 


\section{Introduction}

Achieving optimal coronary flow following thrombolysis in myocardial infarction (TIMI) reduces mortality, preserves left ventricular function and improves survival following acute myocardial infarction (AMI). ${ }^{1,2}$ The prognosis of patients with persistent occlusion of the infarct related artery (IRA), despite lytic therapy is poor compared with that of patients with recanalized coronary arteries. Therefore, early detection of successful reperfusion and IRA patency in patients who received thrombolytic therapy is of great importance in terms of prognosis and identification of candidates for rescue percutaneous coronary intervention (PCI). ${ }^{3}$

For this purpose, some parameters such as: relief of chest pain, early peak of cardiac biomarkers, appearance of reperfusion arrhythmia and various electrocardiographic (ECG) changes are used as noninvasive tools, among which ST segment resolution at 90 minutes is one of the most important markers of successful reperfusion and prognosis. $^{4}$

P wave dispersion (PWD), a parameter measured before and after fibrinolytic therapy (FT) is able to predict successful reperfusion in patients with acute anterior MI. ${ }^{5}$ The P-max is the longest atrial conduction time and $\mathrm{P}$-min is the shortest atrial conduction time measured in any of the 12 leads of the surface ECG. ${ }^{6}$ PWD is calculated by subtracting the minimum $\mathrm{P}$-min from the $\mathrm{P}$-max. ${ }^{7} \mathrm{~A}$ pathological $\mathrm{P}$-wave duration is considered as $\geq 120$ msec. $^{8}$

PWD was found to be significantly increased during the anginal episodes irrespective of the presence of history of a previous myocardial infarction. ${ }^{9}$ Furthermore, PWD showed higher values during the anginal episode in patients with left ventricular dysfunction independently of the presence of a previous myocardial infarction. ${ }^{10}$ PWD at 120 minutes is significantly lower in patients with successful reperfusion and patent IRA. ${ }^{5} \mathrm{P}$-max and PWD is higher in slow coronary flow patient. ${ }^{11}$

\section{Methods:}

This was an observational study conducted in Department of Cardiology, National Institute of Cardiovascular Diseases, Dhaka, Bangladesh from July 2013 to July 2014. After judging against inclusion and exclusion criteria $132 \mathrm{AMI}$ (Anterior) patients were divided into two groups on the basis of ST Segment resolution (STR) after 120 minutes of thrombolysis. Group I: patients with STR >70\%; Group II: patients with STR $<70 \%$.

Streptokinase was used as a thrombolytic agent. 12 lead resting ECG was done at a paper speed of $25 \mathrm{~mm} / \mathrm{s}$ and 10 $\mathrm{mm}$ standardization. All recordings were performed in the same quiet room during spontaneous breathing, following
20 minute of adjustment in the supine position. ST-segment deviation was measured with a handheld caliper and magnifying glass at 80 milliseconds after the J-point in all available leads. The TP-segment was considered the preferred iso-electric baseline and ST segment deviation was measured to the nearest $0.05 \mathrm{mV}$. ST segment resolution was calculated and expressed as a percentage with this formula: (baseline ST elevation-120 minute ST elevation)/baseline ST elevation.

ECGs were recorded before, 90 minutes and 120 minutes after onset of thrombolysis. The onset of the $P$ wave was defined as the point of first visible upward slope from baseline for positive waveforms and as the point of first downward slope from baseline for negative waveforms. The return to the baseline was considered as the end of the $P$ wave. Biphasic $P$ waves were measured to the time of final return to baseline. If the onset or offset of the $P$ wave were not clearly determined the lead was excluded from the analysis. $P$ wave duration measurements were obtained manually by using calipers and magnifying lens for accurate definition of the ECG deflection. PWD of both groups was measured by subtracting $P$ wave minimum from $P$ wave maximum durations.

Transthoracic echocardiography was done for chambers size, wall motion abnormality, EF\%, valvular and pericardial conditions. All patients underwent coronary angiography (CAG). Anterograde perfusion of the infarct-related artery was graded according to the classification system of the thrombolysis in myocardial infarction (TIMI) trial (grade $0=$ no anterograde perfusion, grade $1=$ minimal perfusion, grade 2 = partial perfusion and grade $3=$ complete perfusion). IRA patency was considered if TIMI flow grade was 2 or 3 .

The SPSS Statistical Software (17.0 version, SPSS Inc., Chicago, Illinois, USA) was used for data analysis. Continuous variables were expressed in mean \& standard deviation and categorical variables as frequency and percentage. Student's t-test was used to compare normally distributed continuous variables and for the categorical variables the chi-square test was used. Multiple logistic regression analysis was performed to assess the PWD 120 minutes after onset of thrombolysis (PWD120) as a predictor of reperfusion and IRA patency. A p-value $<0.05$ was considered statistically significant.

\section{Results}

Total 132 patients were studied. The mean age of the studied patients was $50.60 \pm 8.23$ years. The mean age of group I was less than group II, but the difference between two groups was not statistically significant $(p=0.06)$. Male, female ratio was 4.3:1. Male was predominant but no significant difference $(p=0.82)$ was found between the groups. 
Table-I

Comparison of the study groups by their demographic characteristics $(N=132)$

\begin{tabular}{|c|c|c|c|c|c|c|c|}
\hline \multirow[t]{3}{*}{ Age in years } & \multicolumn{4}{|c|}{ STR } & \multirow{2}{*}{\multicolumn{2}{|c|}{ Total $(\mathrm{N}=132)$}} & \multirow[t]{3}{*}{$p$-value } \\
\hline & \multicolumn{2}{|c|}{ Group I $(n=66)$} & \multicolumn{2}{|c|}{ Group II $(n=66)$} & & & \\
\hline & Number & $\%$ & Number & $\%$ & Number & $\%$ & \\
\hline$<40$ & 14 & 21.21 & 11 & 16.67 & 25 & 18.94 & $\mathrm{a} 0.11^{\mathrm{NS}}$ \\
\hline $40-60$ & 40 & 60.61 & 43 & 65.15 & 83 & 62.88 & \\
\hline$>60$ & 12 & 18.18 & 12 & 18.18 & 24 & 18.18 & \\
\hline Mean \pm SD & \multicolumn{2}{|c|}{$49.12 \pm 9.54$} & \multicolumn{2}{|c|}{$52.08 \pm 8.23$} & \multicolumn{2}{|c|}{$50.60 \pm 8.23$} & ${ }^{\mathrm{b}} 0.06^{\mathrm{NS}}$ \\
\hline \multicolumn{8}{|l|}{ Sex } \\
\hline Male & 53 & 80.30 & 54 & 81.82 & 107 & 81.06 & ${ }^{\mathrm{a}} 0.82^{\mathrm{NS}}$ \\
\hline Female & 13 & 19.70 & 12 & 18.18 & 25 & 18.94 & \\
\hline
\end{tabular}

Group I= Patients with STR $>70 \%$

Group II = patients with STR $<70 \%$

STR $=$ ST segment resolution after 120 minutes of thrombolysis

NS $=$ Not significant $(p>0.05)$

${ }^{a} p$ value reached from chi-squared test

$b_{p}$ value reached from unpaired $t$ test

Total 132 patients were studied. The mean age of the studied patients was $50.60 \pm 8.23$ years. The mean age of group I was less than group II, but the difference between two groups was not statistically significant $(p=0.06)$. Male female ratio was 4.3:1. No significant difference $(p=0.82)$ was found between the groups in terms of sex distribution

Table II

Comparison of the study groups by their risk factors $(N=132)$

\begin{tabular}{|c|c|c|c|c|c|c|c|}
\hline \multirow[t]{3}{*}{$\overline{B M}\left(\mathrm{~kg} / \mathrm{m}^{2}\right)$} & \multicolumn{4}{|c|}{ STR } & \multirow{2}{*}{\multicolumn{2}{|c|}{ Total $(\mathrm{N}=132)$}} & \multirow[t]{3}{*}{$p$-value } \\
\hline & \multicolumn{2}{|c|}{ Group I $(n=66)$} & \multicolumn{2}{|c|}{ Group II $(n=66)$} & & & \\
\hline & Number & $\%$ & Number & $\%$ & Number & $\%$ & \\
\hline$\overline{\text { Normal }}$ & 31 & 46.97 & 28 & 42.2 & 59 & 18.94 & ${ }^{\mathrm{a}} 0.33^{\mathrm{NS}}$ \\
\hline Overweight & 22 & 33.33 & 19 & 28.49 & 41 & 62.88 & \\
\hline Obese & 13 & 19.70 & 19 & 28.79 & 32 & 18.18 & \\
\hline Mean \pm SD & $23.42 \pm 3.67$ & $24.78 \pm 4.88$ & $24.10 \pm 4.23$ & $\mathrm{~b}_{0.06^{\mathrm{NS}}}$ & & & \\
\hline \multicolumn{8}{|l|}{ Risk Factors } \\
\hline Smoking & 45 & 68.18 & 40 & 60.61 & 85 & 64.39 & ${ }^{\mathrm{a}} 0.36^{\mathrm{NS}}$ \\
\hline Hypertension & 30 & 45.45 & 35 & 53.03 & 65 & 49.24 & ${ }^{\mathrm{a}} 0.28^{\mathrm{NS}}$ \\
\hline Diabetes & 25 & 37.88 & 37 & 56.06 & 62 & 46.97 & ${ }^{a} 0.04^{s}$ \\
\hline Dyslipidemia & 23 & 34.85 & 35 & 53.03 & 58 & 43.94 & ${ }^{a} 0.03^{s}$ \\
\hline Family history & 10 & 15.15 & 14 & 21.21 & 24 & 18.18 & ${ }^{\mathrm{a}} 0.36^{\mathrm{NS}}$ \\
\hline
\end{tabular}

Group I= Patients with STR $>70 \%$

Group II = patients with STR $<70 \%$

STR $=$ ST segment resolution after 120 minutes of thrombolysis

$\mathrm{BMI}=$ Body Mass Index

NS $=$ Not significant $(p>0.05)$

$S=$ Significant $(p<0.05)$

${ }^{a} p$ value reached from chi-squared test

${ }^{b} p$ value reached from unpaired t test 
BMI demonstrates very close values in both groups with no significant difference between groups $(p=0.33)$. Smoking is higher in group I than in group II $(p=0.36)$. It was observed that diabetes mellitus and dyslipidemia were significantly higher in Group II $(p=0.04, p=0.03)$

Table-III

Comparison of the study groups according to $P$ wave dispersions $(n=132)$

\begin{tabular}{|c|c|c|c|}
\hline \multirow[t]{2}{*}{ PWD (millisecond) } & \multicolumn{2}{|c|}{ STR } & \multirow[t]{2}{*}{$P$ value } \\
\hline & Group I $(n=66)$ & Group II $(n=66)$ & \\
\hline PWD0 & $48.97 \pm 10.72$ & $51.59 \pm 8.34$ & $0.45^{\mathrm{NS}}$ \\
\hline PWD90 & $44.24 \pm 9.12$ & $46.98 \pm 7.44$ & $0.19^{N S}$ \\
\hline PWD120 & $40.86 \pm 7.25$ & $47.91 \pm 6.14$ & $0.001^{\mathrm{s}}$ \\
\hline
\end{tabular}

Group I= Patients with STR $>70 \%$

Group II = patients with STR $<70 \%$

PWD = P Wave Dispersion

STR $=$ ST segment resolution after 120 minutes of thrombolysis

PWD0 $=$ PWD at 0 mimute (before the of onset of thrombolysis)

PWD90 =PWD 90 minutes after onset of thrombolysis

PWD120 =PWD 120 minutes after onset of thrombolysis

NS $=$ Not significant $(p>0.05)$

$S=$ Significant $(p<0.05)$

$p$ value reached from unpaired $t$ test

Between the two groups, the differences of means of PWD0 and PWD90 were not statistically significant ( $p=0.45$ and $p=0.19$, respectively). The difference of mean levels of PWD120 across the groups was statistically significant $(p=0.001)$.

Table-IV

Comparison of the study groups according to infarct related artery (IRA) patency $(n=132)$

\begin{tabular}{|c|c|c|c|c|c|c|c|}
\hline \multirow[t]{3}{*}{$\mathrm{BMI}\left(\mathrm{kg} / \mathrm{m}^{2}\right)$} & \multicolumn{4}{|c|}{ STR } & \multirow{2}{*}{\multicolumn{2}{|c|}{ Total $(\mathrm{N}=132)$}} & \multirow[t]{3}{*}{$p$-value } \\
\hline & \multicolumn{2}{|c|}{ Group I $(n=66)$} & \multicolumn{2}{|c|}{ Group II $(n=66)$} & & & \\
\hline & Number & $\% 1$ & Number & $\%$ & Number & $\%$ & \\
\hline IRA patent & 45 & 68.18 & 10 & 15.15 & 55 & 41.66 & $0.001^{\mathrm{S}}$ \\
\hline IRA occluded & 21 & 31.82 & 56 & 84.85 & 77 & 58.44 & \\
\hline
\end{tabular}

Group I= Patients with STR $>70 \%$

Group II = patients with STR $<70 \%$

$\mathrm{STR}=\mathrm{ST}$ segment resolution after 120 minutes of thrombolysis

IRA = Infarct Related Artery

$S=$ Significant $(p<0.05)$

$p$ value reached from chi-square t test

It was observed that IRA patent patients were more in group I than group II (68.18\% vs. 15.15\%) which was statistically significant $(p=0.001)$.

Table V

Multivariate logistic regression of determinants of ST-segment resolution

\begin{tabular}{lccccc}
\hline Variables of interest & $\beta$ & S.E. & P value & OR & 95\% Cl \\
\hline Smoking & 0.253 & 0.441 & $0.56^{\text {NS }}$ & 1.288 & $0.543-3.055$ \\
Hypertension & 0.701 & 0.501 & $0.10^{\text {NS }}$ & 1.066 & $0.519-2.503$ \\
Diabetes mellitus & 0.367 & 0.506 & $0.46^{\text {NS }}$ & 1.444 & $0.535-3.892$ \\
Dyslipidemia & 0.203 & 0.249 & $0.66^{\text {NS }}$ & 0.816 & $0.325-2.054$ \\
PWD120 & 0.912 & 0.654 & $0.01^{\mathrm{S}}$ & 1.101 & $1.012-1.240$ \\
\hline
\end{tabular}

Dependent variable: ST-segment resolution

Independent variables; smoking, hypertension, diabetes mellitus, dyslipidemia and PWD120

$S=$ Significant $\quad \beta=b$ error $\quad$ OR = Odds ratio

$\mathrm{NS}=$ Not significant $\quad \mathrm{SE}=$ Standard error $\quad \mathrm{Cl}=$ Confidence interval 
The binary logistic regression analysis of Odds Ratio for characteristics of the subjects likely to develop ST segment resolution, among different variables, PWD120 were found to be the significant predictors to develop ST segment resolution (95\% Cl: $1.000-1.260 ; p=0.03)$.

Table-VI

Multivariate logistic regression of determinants of infarct related artery patency

\begin{tabular}{lccccc}
\hline Variables of interest & $\beta$ & S.E. & P value & OR & $95 \% \mathrm{Cl}$ \\
\hline Smoking & 0.253 & 0.441 & $0.56^{\mathrm{NS}}$ & 1.288 & $0.543-3.055$ \\
Hypertension & 0.701 & 0.501 & $0.10^{\mathrm{NS}}$ & 1.066 & $0.519-2.503$ \\
Diabetes mellitus & 0.367 & 0.506 & $0.46^{\mathrm{NS}}$ & 1.444 & $0.535-3.892$ \\
Dyslipidemia & 0.203 & 0.249 & $0.66^{\mathrm{NS}}$ & 0.816 & $0.325-2.054$ \\
PWD120 & 0.912 & 0.654 & $0.01^{\mathrm{S}}$ & 1.101 & $1.012-1.240$ \\
\hline
\end{tabular}

Dependent variable: infarct related artery patency

Independent variables: smoking, hypertension, diabetes mellitus, dyslipidemia and PWD120

$S=$ Significant $\quad \beta=b$ error $\quad$ OR $=$ Odds ratio

$\mathrm{NS}=$ Not significant $\quad \mathrm{SE}=$ Standard error $\quad \mathrm{Cl}=$ Confidence interval

The binary logistic regression analysis of Odds Ratio for characteristics of the subjects likely to cause IRA patency, among different variables, PWD120 was found to be the significant predictor of IRA patency $\left(95 \% \mathrm{Cl}: 1.012-1.240 ; \mathrm{p}=0.01^{\mathrm{S}}\right)$.

\section{Discussion}

In this study, the mean age of the successfully thrombolysed group was $49.12 \pm 9.54$ and mean age of failed thrombolysis group was $52.08 \pm 8.23$ years. Though higher age was associated with failed thrombolysis it was statistically insignificant $(p=0.06)$. In a similar study conducted by Karabag et al. observed that the mean age was higher in failed thrombolysis group. ${ }^{5}$ Successful thrombolysis had higher percentage of male though statistically not significant $(p=0.82)$. Another studyshowed the similar higher percentage of male in successful thrombolysed group. ${ }^{6}$ Patients with higher BMI demonstrated successful thrombolysis as was found in the similar study conducted by Mahmoud. ${ }^{6}$ Among the studied patients, hypertension, diabetes mellitus, dyslipidemia and family history of IHD were higher in group II and smoking was higher in group I. It was also observed that diabetes mellitus and dyslipidemia were significantly higher in Group II ( $p=0.04, p=0.03)$.Another study conducted by Mahmoud 2012, similar results observed in Blood glucose level (78.1 \pm 4$),(p=0.28)$; LDL level $(113 \pm 9.3),(p=0.08)$; and triglyceride level (162.8 \pm 23$),(p=0.76)$ in failed reperfusion group which were similar to this study. ${ }^{6}$

The mean level of PWD120 was statistically significant $(p=0.001)$.Similar observation was conducted by Karabag et al., 2012 showed that the mean PWD at $120 \mathrm{~ms}$ in both groups with AMI (Anterior)were statistically significant $(p=<0.001) .{ }^{5}$ The study conducted by Dilaveris PE, et al., 2006 showed that PWD was significant betweenthe groups of during spontaneous angina periodand asymptomatic period, $\mathrm{P}<0.001^{12}$. Another study by Mahmoud, K, 2012 to evaluate PD, PWD and QT dispersion (QTD) in patients with Coronary Slow Flow (CSF) and its relationship between thrombolysed MI patients group and control group where CSF patients had significant PWD $(P=0.001){ }^{6}$

The multivariate regression analysis of odds ratios for characteristics of the subjects likely to cause IRA patency was studied. Out of the 5 variables, PWD120 was found to be the significant predictor of ST segment resolution as well as IRA patency. Karabag et al. also showed that PWD120 could predict IRA patency and ST-segment resolution on ECG (OR: 0.907, Cl: 0.856 to 0.960; $p=0.001$; OR: 0.942, $\mathrm{Cl}: 0,896$ to 0,$991 ; p=0.02$, respectively) ${ }^{5}$

\section{Conclusion}

From this study, it may be concluded that low $\mathrm{P}$ wave dispersion (PWD) in patients receiving thrombolytic therapy can be a predictor of successful reperfusion and patent infarct related artery (IRA). PWD values, in combination with other reperfusion parameters, can contribute to the identification of rescue $\mathrm{PCl}$ candidates.

\section{Study Limitations:}

This was an observational study on patients who presented to hospital with acute $\mathrm{MI}$ (anterior) and who refused the option of primary $\mathrm{PCl}$. We use streptokinase for thrombolysis which was less superior to other thrombolytics like tenecteplase due to unavailability. Purposive sampling was done instead of random sampling method in my study. Although 90 minutes after thrombolytic therapy is standard time for rescue $\mathrm{PCl}$ in most centers, PWD was measured at 120 minutes in our study. Most of our hypertensive patients were on antihypertensive medications. We could not exclude patients who were using drugs that might affect atrial conduction and PWD like antihypertensive agent. 


\section{Recommendations}

Further prospective studies are needed to assess the temporality of the association between $\mathrm{P}$ wave dispersion (PWD) value and successful reperfusion and IRA patency by ECG following thrombolysis of acute MI (Anterior) patients. Similarly, in future randomized clinical trials using large number of patients may be used.

\section{References:}

1. Fox KAA, Goodman SG, Klein W, Brieger D, Steg PG, Dabbous $\mathrm{O}$, et al. Management of acute coronary syndromes. Variations in practice and outcome; findings from the Global Registry of Acute Coronary Events (GRACE).Eur Heart J. 2002;23:1177-89.

2. Fibrinolytic Therapy Trialists' (FTT) Collaborative Group. Indications for fibrinolytic therapy in suspected acute myocardial infarction: Collaborative overview of early mortality and major morbidity results from all randomised trials of more than 1000 patients. Lancet. 1994;343:311-22.

3. Ross AM, Lundergan CF, Rohrbeck SC, Boyle DH, van den Brand $\mathrm{M}$, Buller $\mathrm{CH}$, et al. Rescue angioplasty after failed thrombolysis: Technical and clinical outcomes in a large thrombolysis trial. GUSTO-1 Angiographic Investigators.Global Utilization of Streptokinase and Tissue Plasminogen Activator for Occluded Coronary Arteries. J Am Coll Cardiol. 1998;31:1511-7.

4. Stewart JT, French JK, Theroux P, Ramanathan K, Solymoss BC, Johnson R, et al. Early noninvasive identification of failed reperfusion after intravenous thrombolytic therapy in acute myocardial infarction.J Am Coll Cardiol. 1998;31:1499-505.
5. Karabag T, Dogan SM, Aydin M, Sayin MR, Buyukuysal $C$, Gudul NE, et al. The value of $P$ wave dispersion in predicting reperfusion and infarct related artery patency in acute anterior myocardial infarction. Clin Invest Med. 2012;35:12-9.

6. Mahmoud K. Effect of coronary slow flow on dispersion of P-wave \& QT-interval and its relationship with Thrombolysis in Myocardial Infarction frame count. The Egyptian Heart Journal. 2013;65:175-80.

7. Agarwal YK, Aronow WS, Levy JA, Spodick DH. Association of interatrial block with development of atrial fibrillation.Am J Cardiol. 2003;91:882.

8. Shturman A, Bickel A, Atar S. The predictive value of $P$-wave duration by signal-averaged electrocardiogram in acute ST elevation myocardial infarction. Isr Med Assoc J. 2012; 14:493-7.

9. Akin F, Firatli I, Katkat F, Gurmen T, Ayca B, Kalyoncuoglu $\mathrm{M}$, et al. P-wave dispersion and its relationship with the severity of the disease in patients with stable coronary artery disease. North Clin Istanb. 2014;1:65-70.

10. Dilaveris PE, Stefanadis CI. P Wave Dispersion: A Valuable Non-Invasive Marker of Vulnerability to Atrial Arrhythmias. Hosp Chron. 2006; 1:130-7.

11. Akcay A, Acar G, Suner A, Sokmen A, Sokmen G, Nacar AB, et al. Effects of slow coronary artery flow on P-wave dispersion and atrial electromechanical coupling. J Endocrinol 2009; 42:328-33.

12. Dilavaris PE, Andrikopoulos GK, Metaxas G, Richter $D J$, et al. Effect of ischemia on $P$ wave dispersion and maximum $P$ wave duration during spontaneous angina episodes. Pacing Clin Electrophysiolol 1999, 22; 11: 1640-7 